\title{
In female supervisors male subordinates trust!? An experiment on supervisor and subordinate gender and the perceptions of tight control
}

\author{
Tobias Johansson $^{1,2}$ (D) Gabriella Wennblom ${ }^{2}$ (D)
}

Published online: 11 May 2017

(C) The Author(s) 2017. This article is an open access publication

\begin{abstract}
Little attention has been directed towards the role of gender in the supervisor-subordinate dyad that is the very fundament of management control. We argue that gender roles and the roles implied in the supervisor-subordinate relationship are powerful concepts that need to be incorporated in research to better understand the reactions and perceptions of management controls. The article contributes to this line of research by developing and testing hypotheses related to gender differences in supervisor-subordinate dyads and the resulting perceptions of evaluation fairness and trust in management under a tight control regime. In a vignette experiment where only the name of the supervisor was changed to a typical female or male name for female and male subordinates (respondents) $(2 \times 2$ ), we find that female (male) subordinates demonstrate more negative (positive) attitudes towards evaluation fairness and that male subordinates with a female supervisor put more trust in management than males with a male supervisor and females with a female supervisor.
\end{abstract}

Keywords Gender · Tight control · Supervisor-subordinate dyad · Fairness · Trust · Experiment

JEL Classifications M10 $\cdot$ M40 $\cdot$ M41

\footnotetext{
$凶$ Tobias Johansson

tobias.johansson@oru.se; tobias.johansson@kau.se

Gabriella Wennblom

gabriella.wennblom@oru.se

1 Karlstad Business School, Karlstad University, Karlstad, Sweden

2 Örebro University Business School, Örebro University, 70182 Örebro, Sweden
} 


\section{Introduction}

In most management control research within the accounting literature that investigates the psychological, behavioural, ethical or performance effects of supervision, evaluation and the control of subordinates in organisations, the supervisor and subordinate dyad is sexless or genderless ${ }^{1}$; the gender of the supervisor and subordinate is silent in theory and most often also in descriptive statistics about the sample (Otley et al. 1995; Parker 2008; Berry et al. 2009). Or perhaps, the dyad is not genderless but implicitly assumed to consist of a male supervisor and probably also of a male subordinate, since this reflects structures and commonly held stereotypes in society and business (Parker 2008). Although males are still overrepresented as supervisors/managers in many industries, the workforce landscape has changed greatly since researchers started to take an interest in management control. Women have not only entered the workforce itself, but have also gradually made an entrance into management positions (Eagly and Carli 2003). This transition has been, and still continues to be, far from easy for many women. Despite these concerns we do not aim to discuss the matter of structural discrimination per se. Instead, we aim to problematise the fact that the supervisor and subordinate dyad, which underpins the vertical relationship in management control, needs to be researched from an additional perspective. In this respect we explicitly acknowledge that the supervisor and subordinate dyad consists of female and male subjects that are under the influence of gender roles, and that this issue may affect how the control situation is perceived and acted upon. Since gender is something that exists within other social structures and strata of society (e.g. within ethnic and socioeconomic groups) it is perhaps the most embedded and common social structure of society and organisations. As such, its neglect in this type of management control research is surprising, or perhaps not (Parker 2008). Although the civil response of some people is likely to be that the gender of supervisors and subordinates is of little importance in modern society and for management control, research within other areas of accounting (e.g. Hull and Umansky 1997; Parker 2008), and other disciplines such as psychology, sociology and experimental economics (e.g. Eagly and Karau 2002; Croson and Gneezy 2009; Muriel and Vesterlund 2011) has shown that this is probably not true. Stereotypical beliefs about the way men and women behave and are supposed to behave (Glick and Fiske 1999), and social roles and group identities involving gender (Eagly and Karau 2002) have been demonstrated as important explanations for expectations and perceptions of behaviour and the resulting behavioural outcomes in hierarchical, competitive and co-operative relationships. From these theories and findings it seems natural that there is a general expectation that similar behaviour in a female or male supervisor may be perceived differently by their subordinates, and that subordinate responses and perceptions of management control design and use may vary depending on the gender of the subordinate. Perhaps even

\footnotetext{
1 We use the terms 'gender' and 'sex' synonymously in this paper. By 'female' and 'male' we mean the way that an individual chooses to classify him-/herself in terms of being a woman or a man. We are aware that gender (also) refers to femininity and masculinity, which is a more fluid concept than the mere classification into sexes (e.g. Parker 2008); however, as does the vast literature on gender/sex, in this article we equate/use the sociobiological classification as a proxy for the two major gender roles in society (female and male).
} 
more surprising and interesting would be a lack of such patterns. All in all, this strongly suggests the relevance of explicitly taking gender roles into account in the relationship between management control design and use and the resulting perceptions of control in supervisor-subordinate dyads.

In this article we contribute to this line of research by developing and testing hypotheses related to gender differences in supervisor-subordinate dyads, and the resulting perceptions of evaluation fairness and trust in management (e.g. Lau and Sholihin 2005; Lau and Tan 2006; Lau et al. 2008; Sholihin and Pike 2009; Hartmann and Slapničar 2009, 2012) under a tight budget control regime (Van der Stede 2001; Johansson and Siverbo 2014). We chose this context and the related outcomes of the control system for several reasons. First, tight (budgetary) control $^{2}$ is a commonly discussed and important control type, or evaluator style, in the management control literature (Hopwood 1972; Otley 1978; Van der Stede 2001). By adding gender to the analysis of this control type, we make a novel contribution at the same time as we position our study at the core of management control research.

Second, and central to our aim, a tight controlling supervisor fits well with what the gender-based leadership literature would regard as an autocratic type of leader, or leadership style, which has stereotypical male traits in it (e.g. Eagly and Carli 2003). Consequently, we theorise that a 'stereotypical masculine control type', as in a tight controlling supervisor, causes variation in how men and woman come to identify with such a control system. In this respect, the relationship between tight budgetary control and gender perceptions becomes important, since identification with different organisational arrangements has been showed to be an effective way of controlling agents' behaviour (Akerlof and Kranton 2005). Theorising of the gender of supervisors and subordinates in contrast to this stereotypical 'male type' of evaluator style thus makes the gender role issue stand out as an intuitively interesting and pressing phenomenon to explore. Does it matter if the tight controlling supervisor is male or female and do females and males respond similarly to tight controls?

Third, the focus on evaluation fairness and trust in management is chosen because they are both concepts and constructs central to management control and organisation research (Colquitt 2001; Hartmann and Slapničar 2009, 2012; Iqbal et al. 2015). For tight controls, and formal controls in general, to be effective (and not counterproductive) it is important that the evaluation and control system is perceived to be fair and just, and that management is trusted; otherwise there is a risk that different kinds of dysfunctions related to short-termism, job-related tension and stress (Hopwood 1972; Otley 1978; Ross 1994), motivational problems (Colquitt et al. 2001) and lack of organisational commitment (Sweeney and McFarlin 1993), outweigh the benefits of increased predictability and control (Van der Stede 2000; Merchant and Van der Stede 2012). Furthermore, the perceived fairness of control systems could also be argued as a central normative dimension on its own, to be valued regardless of its potentially positive performance effects (Cugueró-Escofet and Rosanas 2013).

\footnotetext{
2 Tight (budget) control has been conceptualised as a case where upper management emphasises meeting the budget, does not accept budget revisions, has a detailed interest in specific budget line items, does not tolerate deviations from interim budget targets and is intensively engaged in budget-related communications (Van der Stede 2001; Johansson and Siverbo 2014).
} 
Consequently, the way controls affect trust in management and the perceived fairness of evaluation becomes important, and an area for management control researchers to explore. Researchers have investigated different aspects of the control system and its relationship to individual and contextual factors in order to explain variations in trust and perceived fairness (Hartmann and Slapničar 2009, 2012; Baldvinsdottir et al. 2011; Wennblom 2012). These aspects include, on the one hand, design attributes such as the formality and objectivity of the evaluation process (Hartmann and Slapničar 2009), feedback quality (Coletti et al. 2005; Hartmann and Slapničar 2009), and budget participation (Lau and Buckland 2001; Lau and Tan 2006), and on the other hand features related to how the evaluation process is used and carried out by superiors (Johansson and Baldvinsdottir 2003). However, with the knowledge that research in other disciplines has found evident gender differences in trust and fairness perceptions (e.g. Jeanquart-Barone and Sekaran 1994; Stedham et al. 2007; Buchana et al. 2008) we put forward this factor as a contribution to the analysis of how formal and tight controls affect trust and fairness perceptions. Building on social (gender) role theory (Eagly 1987) and status theory (Ridgeway 1991) we argue that tight control has characteristics that fit with the stereotyped male gender role and hypothesise: (1) that males will report higher levels of trust in management and perceived fairness in a tight control situation, (2) that female, compared to male, supervisors will affect trust in management and evaluation fairness negatively, and we explore (3) if and how the effect of supervisor gender is dependent upon subordinate gender.

To test the hypotheses, we designed a vignette experiment of a tight control business case and distributed it to 192 third- and fourth-year business school students. The experimental design allowed us to systematically elaborate on the gender of subjects in the tight control supervisor-subordinate dyad. The results show that male respondents perceive tight control as fairer than females and that it is only in the case of a female supervisor that subordinate gender becomes important for both trust and fairness perceptions. Furthermore, the results reveal that male subordinates put more trust in a female supervisor than in a male supervisor under a tight control regime.

In the next section, we develop our hypotheses for the expected gender differences in evaluation fairness and trust in management under a tight control regime. In the section after that, the experimental design and measurement properties are presented. In the penultimate section, we conduct the statistical test of our hypotheses and factorial design. In the final section, we discuss our findings.

\section{Theory and hypotheses development}

\subsection{Gender roles and the tight control supervisor-subordinate relationship}

In this article we build on social-role theory (Eagly 1987) and status theory (Ridgeway 1991). Social role theory and status theory propose that different societal and organisational roles are infused by socially shared expectations and beliefs about accepted behaviour, dependent on hierarchical positions in organisations and society. These socially shared (cultural) beliefs link greater social significance and general competence with one category of a social distinction (e.g. men) compared to another social 
category (e.g. woman) (Ridgeway 2001). Among a variety of social roles, the gender role is a powerful concept that affects people's beliefs about men and women (e.g. Eagly and Karau 2002; Ridgeway et al. 2009). These beliefs are both descriptive and prescriptive in the sense that they affect how we expect men and women to behave and how we mean they ought to behave (Eagly and Karau 2002), and make gender roles very pervasive in society. Social differences (e.g. gender) turn into status beliefs and hierarchies instantly and locally, and diffuse quickly (Ridgeway and Balkwell 1997; Ridgeway et al. 2009). Gender roles thus have the potential to be an important concept that affect how control in the supervisor-subordinate dyad is perceived, acted upon and made sense of, depending on the gender composition of the relationship.

Social role theory further suggests that differences in societal roles lead men and women to display and value different types of interpersonal behaviours (Eagly 1987; Eagly and Johannesen-Schmidt 2001) and that men and women respond differently to various aspects of a social relationship. Behaviour and social relationships have been categorised in two dimensions; communal and agentic (Bakan 1966; Eagly 1987; Koenig et al. 2011). The communal dimension is interpersonally oriented and broadly described as showing concern for the welfare of others (e.g. nurturing, sympathetic, friendly, democratic) (Eagly 1987, 2009; Spence and Buckner 2000). The agentic dimension is task-oriented and defined by independent, masterful, and assertive tendencies (e.g. competitive, ambitious, dominating) (Eagly 1987; Spence and Buckner 2000; Eagly and Johannesen-Schmidt 2001). Because men are traditionally ascribed with a more agentic behaviour, and women traditionally with more communal behaviour (Eagly 1987; Koenig et al. 2011), this is also expected to affect how we as men and women perceive and respond to hierarchical relationships.

One type of supervisor-subordinate relationship is found in a tight control situation (Van der Stede 2001). Tight control, or tight budgetary control, can be characterised as autocratic, masterful and assertive, since it is top-down, builds on control rather than trust (Vosselman and van der Meer-Kooistra 2009) and on contingent rewards (Bass 1985; Avolio 1999; Van der Stede 2001). As such, it is clearly more in tune with agentic behaviour (masterfulness, domination, competition) and stereotypically male types of activities than with communal behaviour (nurturing, friendliness, democratic) and stereotypically female types of activities (Eagly and Carli 2003). Tight control, as a concept and practice, can in this respect be viewed as a typical agentic and 'male type' of evaluation style. In the text below, we develop arguments on the way in which the categorisation of our self and others as being a male or female is related to perceptions of evaluation fairness and trust in management in relation to a tight controlling supervisor.

As will be developed in the method section, our experiment builds on a case where the control system is being tightened and it is how this type of evaluation style is perceived differently, by varying the gender in the supervisor-subordinate dyad, in terms of evaluation fairness and management trustworthiness that we aim to explain. Because tight and autocratic control is clearly more in tune with agentic and stereotypical male behaviour (the male gender role), we expect males, compared to females, to devalue tight control less and accept such control more. The reason is that they can identify more strongly with such behaviour and may also be more accustomed to such behaviour from their social interactions (with other males). Accordingly, from a social 
role theory perspective we argue that because tight and autocratic control is less in tune with stereotypical female behaviour, we expect females, compared to males, to devalue tight control more in terms of evaluation fairness and management trustworthiness since they can identify less strongly with such behaviour. This argument is also supported by the experimental economics literature, which has demonstrated that males, relative to females, favour competition and perform better in competitive and autocratic environments, the explanation being differences in risk-taking, where females are often found to be more risk-averse (Croson and Gneezy 2009). This claimed difference in risk-taking between the sexes resonates with the communal and agentic types of behaviour incorporated in the social role of females and males. The experimental economics literature also argues that men perceive a task as more instrumental (compared to women) and consequently will have higher expectations regarding the contingent reward. And further, high expectations regarding future rewards is shown to be highly associated with trust for the one who gives the reward (Buchana et al. 2008). The reward dimension in a tight control situation can consequently be a powerful force in causing trustworthiness perceptions, but this seems to hold only for males and not for females (Ibid). Females instead seem to perceive the task as less instrumental and instead as more communal and will consequently not expect much reward, and this will cause females to develop less trust. In conclusion, building on social role theory and supporting arguments from the experimental economics literature, we hold that due to the better (worse) fit between traits prescribed to the male (female) gender role and a tight controlling supervisor, men (women), through their identification with a male gender role, could be argued to have a higher (lower) threshold when tight formal controls exceed what is necessary for neutralising legitimate mistrust (cf. Tenbrunsel and Messick 1999; Vosselman and van der Meer-Kooistra 2009;) between parties in the supervisor-subordinate dyad. Consequently, they will perceive management as more (less) trustworthy and the evaluation as (less) fairer. We therefore propose the following hypotheses (H1 a and b) ${ }^{3}$ :

H1a Under a tight control regime male (females) subordinates perceive evaluation to be fairer (less fair).

H1b Under a tight control regime male (females) subordinates trust management more (less).

In a wide variety of contexts, the literature on leadership and gender has shown that both male and female superiors are impacted by gender stereotypes (e.g. Eagly and Carli 2003). Female superiors are expected to show warmth and concern for others and are associated with communal traits and more strongly caretaking roles (Rudman and Glick 2001). The stereotypical characteristics of females do not match the stereotypical picture of a manager/superior, and specifically not the autocratic leadership style as a characteristic of tight control. Autocratic, tight control fits more closely with the way that men are expected to control and lead than the way woman are expected to control and lead, and woman are less likely than men to be associated with autocratic and tight control (Eagly and Johnson 1990; Eagly et al. 1992; Eagly and Karau 2002). Female

\footnotetext{
3 For readability purposes and to be able to discriminate (rejection/corroboration) between the two outcomes (fairness and trust) we split the hypotheses (H1 and H2) into two versions.
} 
superiors who utilise an autocratic control style and show agentic behaviour can consequently be perceived as less congruent with their societal role (Eagly and Karau 2002; Eagly and Carli 2003) and provoke a "backlash" reaction from subordinates (Rudman and Glick 2001). Since men are associated with agentic traits (Rudman and Glick 2001), and with authority and managerial roles (Rudman and Kilanski 2000), male superiors who utilise an autocratic control style such as tight budget control, and show agentic behaviour, are consequently perceived as more congruent with their societal role and more accepted as superiors. The supervisor is the spokesperson and symbol of the evaluation system and the role congruence, or role incongruence, depending on the gender of the supervisor in a tight control context, leads the evaluation system to be perceived differently in terms of (supervisor) behavioural consistency (Eagly and Carli 2003). Behavioural (in)consistency and integrity has been demonstrated to drive both fairness perceptions of evaluation systems (Hartmann and Slapničar 2009) and trustworthiness of management (Whitener et al. 1998). In this case behavioural consistency and integrity refers to what subordinates expect from male and female supervisors in relation to gender roles and what they experience from a tight controlling supervisor. Consequently, we expect that female superiors will be perceived as less fair and trustworthy than male superiors in a tight control situation. This is because females executing tight controls demonstrate role incongruence compared to their social (communal and feminine niceness) role.

H2a Under a tight control regime subordinates with a female (male) superior will perceive the evaluation as less (more) fair than subordinates with a male (female) superior.

H2b Under a tight control regime subordinates with a female (male) superior will trust management less (more) than subordinates with a male (female) superior.

When it comes to potential interaction effects between the two gender subjects in the subordinate-superior dyad, theory is less clear and consistent on how this plays out. One direction, and perhaps the most straightforward and common view, that has been proposed is that the matter of role incongruence and the backlash effect on autocratic female superiors is likely to be more salient to male subordinates, since males tend to have less experience with females taking a superior role and thus have a less neutral, and more male-oriented view of the social category of autocratic (tight) supervisors (Schein 2001; Eagly and Karau 2002). The expectation would thus be that the negative effect of a female superior executing tight control (H2a) is stronger for male subordinates. Another line of reasoning, however, is instead that a female superior is trusted more and perceived as fairer than a male superior by male subordinates simply because male subordinates feel less threatened and dominated by a female superior than a male one due to the lower status of female leaders (Ridgeway 2001). The relatively less aggression and power ascribed to the stereotyped female social role (Eagly and Karau 2002) means that male subordinates feel that they need not worry as much about the consequences of their (poor) performance and behaviour because a female superior is believed less likely to have the power to 'break the order', and thus they dare accept greater vulnerability (i.e. trust) and would also likely perceive the evaluation as less threatening. This implies that male subordinates with a female supervisor would instead perceive the evaluation as fairer and (dare) trust management more than female 
subordinates with a female superior and male subordinates with a male supervisor. Thus, from a social-role (role incongruence) and status perspective it is not clear exactly how these gender interactions in a stereotypical agentic (male) tight control subordinate-superior dyad would actually affect perceptions of the evaluation. Thus, instead of posing a directional hypothesis to be tested we pose a research question exploring if and how this interaction plays out.

RQ1 Under a tight control regime, (how) does subordinate and superior gender interact in affecting evaluation fairness and trust in management?

\section{Method}

\subsection{The vignette-experiment design}

To test our hypotheses we designed a vignette experiment involving a business and evaluation case of tight budgetary control (a constant) and altered only the name of the supervisor to a typical male or female name (Kristina or Markus), referring to them as 'he' or 'she' for male and female respondents (subordinates) making it a $2 \times 2$ factorial design. We instructed the participants to take the role of the subordinate (we used the term SBU manager) and thus changed the name of the subordinate in the case depending on the gender of the respondent (to a male or female name) to make the superior-subordinate gender composition explicit. The experimental design of varying supervisor gender while keeping the situation constant in all other instances, builds on the so-called Goldberg paradigm (1968), which involved differences in text evaluations depending on the gender of the author (and gender of the respondent). This type of experimental design then spread and has been adopted for studying many different aspects of gender bias in evaluation, such as the evaluation of job candidates and leaders (Swim et al. 1989; Eagly and Carli 2003). The strength of the Goldberg design is its simplicity; keeping all other information constant and only altering the name of the subject to one that is male or female has the potential to produce differences in how the subject or case is perceived.

Vignette experiments, and other types of scenario or case-based experiments, are becoming more and more common in management accounting research (e.g. Hartmann and Maas 2010; Kunz and Linder 2012; Cheng and Coyte 2014; Kunz 2015; Gopalakrishnan et al. 2015) and have a long tradition in other areas of social science (Finch 1987). In comparison with other types of experiments, vignette experiments are especially suited for recording perceptions, such as perceptions about fairness and trust, which are not observable traits (Kunz and Linder 2012). To be effective, the validity and relevance of the case becomes important. Thus, it is important to build on other experiments or a deep grounding in practice, and to rely on a sound theoretical base (Taylor 2006). We followed the structure of Hartmann and Maas (2010) when developing the story of the company and the context, and constructed the case to capture Van der Stede's (2001) conceptualisation of tight budgetary control. The vignette was developed to capture an evaluation case where upper management emphasises meeting the budget, does not accept budget revisions, has a detailed interest in specific budget line items, does not tolerate deviations from interim budget targets and is 
intensively engaged in budget-related communications (Van der Stede 2001; Johansson and Siverbo 2014). To strengthen the tight-control case (Van der Stede 2000) and its connection with fairness (Fortin 2008) and trust, we ended the case with a mild moral dilemma where a legal, but perhaps not quite morally right (towards management), data manipulation was presented, aimed at a short-term boost in accounting performance. The case is disclosed in the "Appendix". The case and experiment design was tested on a pilot sample $(n=20)$ of students not included in the experiment. The test showed that the factorial design produced variation in our measures, and that they regarded the control situation as tight (avg. 5.25 on a 7 point scale).

\subsection{The participants}

We enrolled business administration students in their third or fourth year ${ }^{4}$ at a university in Sweden as participants in the experiment. They represent a group that is close to entering working life (in comparison to, for example, undergraduate first-year students who are often targeted in experiments) and will soon be experiencing situations such as the one described in the case. The way they respond to the matters raised in this article is thus also relevant for real life situations in organisations. In these educational programmes there are generally as many women as men students. None of the authors taught on the courses that they took at that time. We attended the classrooms used for the course and asked if the students would like to take part in our investigation. Both in our oral presentation and in the introduction to the case we emphasised that participation was voluntary, that we were interested in their opinions about the case, and that there were no right or wrong answers to the questions about the case. Three individuals chose not to participate and 194 took part in the study. Two participants handed in questionnaires containing mostly blank answers, which were deemed unusable. Of the 192 usable observations, 97 were from females and 95 males, and their average age were 23.5 years (a minimum of 20 and a maximum of 47). 93 out of 192 observations were cases with a female superior.

\subsection{Measures}

Our measure of evaluation fairness is adopted and adapted from Hartmann and Slapničar (2009) who in turn build their measure on the more general fairness literature (e.g. Colquitt 2001). Fairness is a multifaceted concept and consists of different subdimensions (Colquitt 2001). In this research we are interested in how fairly, or justly, respondents rate the performance evaluation in the case and thus focus on the procedural justice aspect of the tight budget control system in use. A sample item of this index variable is: 'XXXX (subordinate name) is evaluated in a fair manner'. The Cronbach's alpha for this scale is 0.818 and the average variance extracted (AVE)(using PCA) is 0.650 implying good internal reliability and unidimensionality.

\footnotetext{
4 At this University the most common business school education program lasts four years.
} 
Our measure of trust in management is adopted and adapted from Hartmann and Slapničar (2009), who build on items developed by Read (1962) that capture how trustworthy management is perceived when it comes to goodwill and integrity. Mayer et al. (1995), and Mayer and Davis (1999), however, have shown that benevolence is also an important element of trust in management. In addition to the three items used by Hartmann and Slapničar, we added an item related to management interest in the needs and desires of subordinates (Mayer and Davis 1999). The Cronbach's alpha for this scale is 0.731 and the AVE is 0.556 , implying good internal reliability and unidimensionality. The square root of the AVE is below the correlation between evaluation fairness and trust in management (see "Appendix"), which indicates discriminate validity between the constructs (Fornell and Larcker 1981). The stricter heterotrait-monotrait (HTMT) ratio used to assess discriminant validity shows that the item inter-correlation $(\mathrm{HTMT}=0.688)$ between evaluation fairness and trust in management is well below the suggested 85 per cent ratio (Henseler et al. 2015).

In addition to our randomised design we include control variables that are dispositions, which could explain why a person is more or less trusting and has a more or less strong apprehension of fairness, per se. First we include the respondent's age as an indication of life experience, potentially affecting (positively or negatively) how much trust is placed in authorities and colleagues (e.g. Uslaner 2000). An older person has more experiences in life, forming a sense of justice and morals. Age is used to capture variation in such experiences. Age is measured as the respondent's stated age in years. We also include the level of generalised trust. Large-scale surveys of people's inclination to trust fellow citizens (generalised trust) in societies have shown that males tend to be higher in trust than females; one suggestion for this is that females are less likely to take risks (Miller and Mitamura 2003). Generalised trust may spill over into trust in other relationships (with management) as well. Generalised trust was measured by asking: 'in general, to what extent can people be trusted?' (Not at all 1, to a very great extent 7)(Kumlin and Rothstein 2010). Thirdly, we include level of social capital in terms of engagement in voluntary associations. Putnam $(1993,2000)$ has argued and demonstrated that this is an important arena where people build experiences beneficial for fostering trust. We argue that this arena (voluntary organisations) also means people gather experiences where they learn to make compromises and value other people's views and hence may have a more nuanced understanding of what is fair and not fair behaviour and treatment in organisations. Social capital is measured as membership (number; none, 1-2, 3-4, 5-6, 7-more) of voluntary associations (sororities, political parties, sports clubs, interest groups, nature and outdoor clubs etc.) (Putnam 1993, 2000). These three questions were asked before participants read the case. Fourth and finally, we include a variable that we call 'moral stand'. As developed above, the case includes a moral dilemma and the stand taken by respondents in the experiment is used as an indication of ethical judgment (Stedham et al. 2007). Research has found that women are more extreme in their assessment of behaviour as wrong, are more focused on personal and relationship-oriented elements, and tend to judge behaviour in organisations as more unfair (ibid). To control for this potential general gender bias in ethical judgment, we include moral stand as an indication of whether ethical judgment potentially affects the perceptions of fairness of the evaluation in the case. Moral stand is captured by asking the respondents how probable $(0-100 \%)$ it is that 
Table 1 Descriptive statistics

\begin{tabular}{lclrrrr}
\hline & Minimum & Maximum & Mean & Std. Deviation & Skewness & Kurtosis \\
\hline $\begin{array}{l}\text { Evaluation } \\
\text { fairness }\end{array}$ & 1 & 7 & 3.24 & 1.27 & 0.422 & -0.241 \\
$\begin{array}{l}\text { Trust in } \\
\quad \text { management }\end{array}$ & 1 & 6.25 & 3.02 & 1.09 & 0.439 & -0.018 \\
Age & 20 & 47 & 23.55 & 3.05 & 3.368 & 19.907 \\
$\begin{array}{l}\text { Generalised } \\
\text { trust }\end{array}$ & 1 & 7 & 4.32 & 1.23 & -0.147 & -0.293 \\
$\quad$ Social capital & 0 & 6 & 1.65 & 1.40 & 1.008 & 1.314 \\
$\quad$ Moral stand & 0 & 100 & 51.77 & 29.39 & -0.034 & -0.938 \\
\hline
\end{tabular}

they, if in the same situation, would have engaged in altering the depreciation rule (cf. Stedham et al. 2007; Hartmann and Maas 2010). This was an exit question for the case.

In Table 1, descriptive statistics are presented and a correlation matrix is included in the "Appendix" (Table 5). In the "Appendix" we also display descriptive statistics per experimental group (Table 4).

\section{Results}

To test the main effects (H1a, H1b and H2a, H2b) and the interaction effect (RQ1) of our $2 \times 2$ factorial design (subordinate and superior gender) connected to our two dependent variables, evaluation fairness and trust in management, and the control variables, we use MANCOVA. Levene's test of homogeneity of variance between the groups shows that the assumption of equal variance is not violated (Evaluation Fairness sig. 0.760 and Trust in Management sig. 0.172). The result of the MANCOVA is presented in Table 2. Subordinate gender (i.e. gender of respondent) has a significant direct effect on both evaluation fairness and trust in management. Superior gender has no direct effects $(p>0.1)$. The interaction between subordinate and superior gender is clearly significant for trust in management, but not for evaluation fairness. Regarding the control variables (covariates), only social capital has a significant effect on evaluation fairness. The model explains about $13 \%$ of the variation in evaluation fairness and $10 \%$ in trust in management.

Although Table 2 shows that there is an (main) effect of subordinate gender on both fairness and trust, the significant interaction between subordinate and superior gender for trust in management makes the interpretation of the main effect for trust in management subject to further analysis. To further explore the substance and meaning of the main and interaction effects for the hypothesis testing, the mean values of the dependent variables for each group are presented in Table 3 and Fig. 1. Starting with hypothesis 1 (a, b) Table 3 and Fig. 1 naturally, due to the nonsignificant interaction, support the finding that male respondents (subordinates) differ from female respondents by experiencing evaluation as fairer even when considering the interaction. Their mean value is consistently above females for both types of superiors. In the case of 
Table 2 MANCOVA

\begin{tabular}{|c|c|c|c|c|c|c|c|}
\hline & DV & $\begin{array}{l}\text { Sum of } \\
\text { squares }\end{array}$ & df & $\begin{array}{l}\text { Mean } \\
\text { square }\end{array}$ & $\mathrm{F}$ & Sig. & $\begin{array}{l}\text { Partial Eta } \\
\text { squared }\end{array}$ \\
\hline \multirow[t]{2}{*}{ Intercept } & Fairness & 46.217 & 1 & 46.217 & 31.681 & 0.000 & 0.148 \\
\hline & Trust & 22.904 & 1 & 22.904 & 20.596 & 0.000 & 0.101 \\
\hline \multirow[t]{2}{*}{ Subordinate gender } & Fairness & 25.685 & 1 & 25.685 & 17.607 & 0.000 & 0.088 \\
\hline & Trust & 8.99 & 1 & 8.99 & 8.084 & 0.003 & 0.042 \\
\hline \multirow[t]{2}{*}{ Superior gender } & Fairness & 0.727 & 1 & 0.727 & 0.498 & 0.241 & 0.003 \\
\hline & Trust & 0.730 & 1 & 0.730 & 0.656 & 0.210 & 0.004 \\
\hline \multirow[t]{2}{*}{ Subgender $\times$ Supgender } & Fairness & 3.735 & 1 & 3.735 & 2.560 & 0.112 & 0.014 \\
\hline & Trust & 5.379 & 1 & 5.379 & 4.837 & 0.030 & 0.026 \\
\hline \multicolumn{8}{|l|}{ Covariates } \\
\hline \multirow[t]{2}{*}{ Age } & Fairness & 4.532 & 1 & 4.532 & 3.107 & 0.080 & 0.017 \\
\hline & Trust & 0.63 & 1 & 0.63 & 0.566 & 0.453 & 0.003 \\
\hline \multirow[t]{2}{*}{ Generalised trust } & Fairness & 0.478 & 1 & 0.478 & 0.328 & 0.568 & 0.002 \\
\hline & Trust & 1.705 & 1 & 1.705 & 1.533 & 0.217 & 0.008 \\
\hline \multirow[t]{2}{*}{ Social capital } & Fairness & 9.002 & 1 & 9.002 & 6.171 & 0.014 & 0.033 \\
\hline & Trust & 3.573 & 1 & 3.573 & 3.213 & 0.075 & 0.017 \\
\hline \multirow[t]{2}{*}{ Moral stand } & Fairness & 0.302 & 1 & 0.302 & 0.207 & 0.650 & 0.001 \\
\hline & Trust & 1.314 & 1 & 1.314 & 1.182 & 0.278 & 0.006 \\
\hline \multirow[t]{2}{*}{ Error } & Fairness & 266.961 & 183 & 1.459 & & & \\
\hline & Trust & 203.51 & 183 & 1.112 & & & \\
\hline \multirow[t]{2}{*}{ Total } & Fairness & 2311.25 & 191 & & & & \\
\hline & Trust & 1970.188 & 191 & & & & \\
\hline \multirow[t]{2}{*}{ Corrected Total } & Fairness & 308.411 & 190 & & & & \\
\hline & Trust & 225.593 & 190 & & & & \\
\hline \multirow[t]{2}{*}{ Model fit } & Fairness & 41.45 & 7 & 5.921 & 4.059 & 0.000 & $0.134\left(R^{2}\right)$ \\
\hline & Trust & 22.083 & 7 & 3.155 & 2.837 & 0.008 & $0.098\left(R^{2}\right)$ \\
\hline
\end{tabular}

trust in management there is, however, no main effect of subordinate gender (Table 3 and Fig. 1). The difference is only present (conditional on) for subordinates having a female superior. In these instances the difference is positive in the sense that for subjects facing a female superior, male subordinates both perceive the evaluation as fairer and trust management more than female subordinates. Hypothesis 1 (H1), focusing on the main effect of subordinate gender is thus partially supported. There is only a main effect of subordinate gender across the two superior gender types for evaluation fairness. When facing a female superior it is interesting to note that the difference is evident for both evaluation fairness and trust in management (Table 3). In conclusion, however, this means that $\mathrm{H} 1_{\mathrm{a}}$ is corroborated and that $\mathrm{H} 1_{\mathrm{b}}$ is rejected. Regarding hypothesis 2 (a, b), neither Tables 2, 3 or Fig. 1 supports there being a main effect of superior gender, and hypothesis two is thus rejected. Concerning the RQ about the conditional effect of superior gender depending on subordinate gender, Table 2 shows that there is a significant interaction in explaining variation in trust in management, 
Table 3 Group mean values of evaluation fairness and trust in management for the four experimental groups

\begin{tabular}{|c|c|c|c|}
\hline Perceived fairness & Male superior & Female superior & Total \\
\hline Male subordinate & 3.32 & $3.81_{4}$ & 3.56 \\
\hline Female subordinate & 2.95 & $2.88^{\frac{1}{7}}$ & 2.91 \\
\hline Total & 3.13 & 3.34 & \\
\hline Trust in management & Male superior & Female superior & \\
\hline Male subordinate & $2.96 \longleftarrow$ & 3.48 & 3.22 \\
\hline Female subordinate & 2.91 & $2.73^{7}$ & 2.82 \\
\hline Total & 2.93 & 3.10 & \\
\hline
\end{tabular}
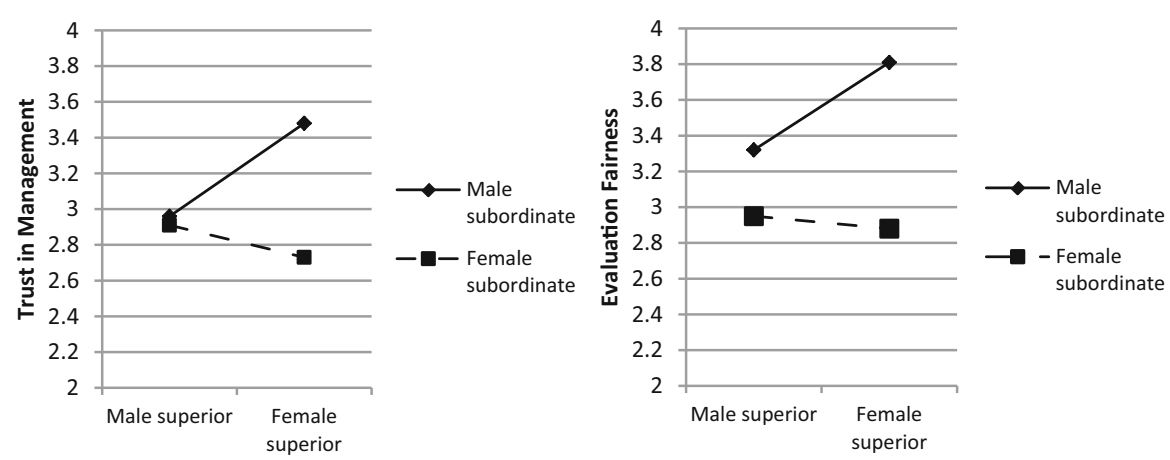

Fig. 1 Conditional effect of superior gender for male and female subordinates

but not for evaluation fairness. As formally tested in Table 2 Fig. 1 explicates that the effect of superior gender differs for male and female subordinates in explaining trust in management (left-hand side of Fig. 1). Performing simple slope tests (Cohen et al. 2003) of the two slopes for trust in management (as plotted in Fig. 1), it is only the slope for male subordinates that is significantly different from zero $(p<0.05)$. Whilst the difference in slope between the two groups is significant (Table 2), the simple effect within the female subordinate (respondent) group is not. As such we can conclude that for male subordinates the gender of the supervisor is important and the effect is that male subordinates with a female supervisor trust management more than male subordinates with a male superior.

\subsection{Additional validations}

Because the measure of social capital is not equidistant and the variable Age has a high kurtosis, we also ran a model with social capital as a number of dummy variables and Age expressed as its logarithm. No other results appeared. To determine whether the control situation is perceived as tight, and to control for whether it is differences 
in perceived tightness of controls that explain differences in fairness and trust, we included the question "how intrusive and strict would you say the evaluation and control that [subordinate name] experiences is?"5 ranging from "not at all tight" to "very tight" (1-7). The mean of the variable was 5.56 and an ANOVA showed no statistical, or substantial, differences between the four groups $(2 \times 2)(p=0.865)$. This means that regardless of whether they have a female or male superior, or are a male or female respondent, participants uniformly regarded the control situation as tight. We asked for the sex of the respondent to check our classification based upon our perceptions (physical appearance) of them being a male or a female, and in all cases our classification matched their own classification. We did not ask for the gender of the superior. The major reason was that, if we had done so, the respondents may have taken this into consideration in their replies (we wanted a first-hand response), and they might perhaps have gone back and deleted or altered answers or decided not to hand in the questionnaire. We chose, from a Swedish perspective, typical female and male names (Kristina and Markus), and referred to them as she and he several times in order to make the gender explicitly visible. As an external validation ten (five males and five females) fourth year students not included in the study (one year later) were asked to mark (in a questionnaire) the gender of the supervisor after having read the case. All ten marked the correct (implied) alternative.

\section{Discussion, limitations and suggestions for future research}

We set out to problematise the fact that the gender of individuals in supervisorsubordinate dyads in the mainstream accounting and control literature is silent, although we know from other disciplines that the gender (roles) of supervisors and subordinates does matter for perceptions and behaviour (e.g. Eagly and Carli 2003). As a first step to more systematically and thoroughly starting to focus on this issue, we conducted a vignette experiment investigating perceptions of evaluation fairness and trust in management in a tight control situation depending on superior and subordinate gender. Along with, for example, the focus on formality and the feedback quality of controls (Coletti et al. 2005; Hartmann and Slapničar 2009), the role of the choice of performance metrics (Lau and Sholihin 2005; Hartmann and Slapničar 2012), the role of formality in performance measurement systems and tolerance of ambiguity (Hartmann and Slapničar 2012), budgeting participation (Lau and Buckland 2001) and the way the performance evaluation process is carried out (Johansson and Baldvinsdottir 2003) for trust in management and fairness perceptions of controls, our study shows that the gender of individuals in the supervisor-subordinate dyad is also a concept affecting perceptions of controls when placed in a tight control context (Van der Stede 2001). Building on influential theories within psychology and leadership research about gender roles and gender role bias, we hypothesised that male subordinates are more accustomed to tight and autocratic contexts and thus respond less negatively to such controls, and that female superiors are seen as less congruent with

\footnotetext{
5 In Swedish the English word tight, as in tight control, is well captured by the two words (synonyms) intrusive and strict.
} 
their social role in a tight control situation and will therefore evoke a more negative reaction than male superiors. Further, we argued that the effect of interactions between gender types in subordinate-superior dyads on control perceptions is not clear from a theoretical perspective and posed a research question exploring if and how the gender of subordinates and superiors interacts in explaining fairness and trust perceptions of control.

\subsection{Subordinate gender}

Our results show that male subordinates (respondents) generally perceive the tight control evaluation as fairer. For cases of a female supervisor, male respondents, compared to females, also put more trust in management. Importantly for this study, the perception of tightness is unaffected by subordinate or superior gender, but it is the perception of how it affects evaluation fairness that differs depending on gender. In that sense it could be argued that male subordinates are better suited to a tight control environment because the tight control of male subordinates would not produce the same amount of behavioural dysfunction (e.g. Hartmann 2000; Van der Stede 2000). This is because perceived fairness of controls is an important buffer against dysfunctional behaviour as a result of controls, and important for positive attitudes generally (Colquitt et al. 2001; Hartmann and Slapničar 2009, 2012). Importantly, however, this should not be taken as evidence that male subordinates are preferable in tougher situations, but simply that males in some instances are more suited to control contexts dominated by traits embedded in the male gender role. This study does not give guidance on the appropriateness of such traits.

The effects of subordinate gender for fairness perceptions and trust in management found in this study indicate that it is important to include the gender of the subordinate in studies investigating how the design and use of formal controls in hierarchical relations affect perceptions of control also more generally. If a sample of respondents is biased towards male respondents (which past studies probably are), our results indicate that positive attitudes might be biased upwards in the collective knowledge about the effects of formal, tight and traditional forms of control (Chenhall 2003). If, instead, research is performed in a female-dominated work context, we might expect more negative (less positive) attitudes towards the control system and management to be more prevalent. According to our results, the matter of subordinate gender under a tight control regime is of particular importance when the superior is a female. For example, Johansson and Siverbo (2014) argue that little attention has been paid towards (tight) budget-control-related outcomes in the public sector. One, perhaps unintended, consequence of this is that the literature may not only be biased sector-wise, but also gender-wise. Public sector organisations (especially social, health, and child care and education) often involve a work force dominated by women and a prevalence of female superiors (Mandel 2012). In this respect, our results indicate that it is not only differences in institutional arrangements and control problem rationales between the private and public that may explain differences in the appropriateness of tight controls, as Johansson and Siverbo (2014) argue, but also the gender composition of subordinates and supervisors in different industries and type of organisations. 


\subsection{Supervisor gender and supervisor-subordinate gender interactions}

Our results are less clear regarding the theorised effect of a superior's gender. First, we find no evidence to support the argument that female superiors, in general, evoke more negative reactions through the use of tight control. In our sample the theorised role incongruence of female superiors with a tight control evaluator style does not seem to create a backlash effect of less positive/more negative attitudes towards tight controls. Second, we find that under a tight control regime male subordinates (respondents) with a female superior, clearly trust management more than males who have a male superior or females who have a female superior. Hence, a superior's gender does have an evident effect in one instance. This particular result shows that interactions between the gender of subjects in the supervisor-subordinate dyad matter and relate back to the explorative research question posed in relation to this. From social-role theory and status theory we identified arguments predicting both an increased and decreased negative bias towards female supervisors for male subordinates. Our results show that in this particular setting male subordinates having a female superior perceive management as more trustworthy than the other combinations.

Since the result is only apparent for trust in management and not for perceptions about evaluation fairness, one probable explanation is to consider the differences in exposure to vulnerability that males feel depending on the gender of the supervisor. Trust is often defined as the willingness to accept vulnerability (e.g. Schoorman et al. 2007), and our results suggests that male subordinates with a female superior seem to accept greater vulnerability in relation to management under a tight control regime. The communal and supporting social role that females are proscribed in most societies does not seem to lead to a significant problem of role incongruence in relation to (agentic) tight control, but instead causes men to feel less vulnerable in relation to female superiors than to males. Again, it is important to note that male subordinates with a female superior do not perceive the control context as less tight than do the others, but still trust management more. As such, female superiors, compared to male superiors, seem to have a leadership advantage when it comes to executing tight control of male subordinates. Traditionally, the female leadership advantage refers to women having leadership styles and qualities supporting subordinates rather than constraining them and that they have a leadership disadvantage in masculine environments (Eagly and Carli 2003). Our study indicates that this advantage may also exists in autocratic and male type of control contexts since having management trust in tight controlling contexts is important for not producing behavioural dysfunctions of tight control.

As argued in the theory section, the interpretation of the increased trust in management for males with a female superior is that a female superior is trusted more than a male superior because, due to the lower status of female leaders (Ridgeway 2001), male subordinates feel less threatened and dominated by a female superior and thus dare trust a female superior more. As such this may speak against the notion that our finding points towards female superiors having a leadership advantage in tight control situations since the theorised lack of perceived domination may also mean that female superiors face difficulties in influencing subordinates in other respects (Ellyson et al. 1992). Although the Goldman paradigm design is appealing because of its simplicity 
(keeping all other information constant and altering the name of the subject only), our rudimentary $2 \times 2$ experiment design needs to be extended to more directly pinpoint and uncover this relationship. Future studies should implement additional constructs such as status and domination and also relate it to other outcomes of tight control in order to accomplish this. An interesting question for future research on gender bias in management control perceptions is thus: why do men seem to trust female superiors more than male superiors when being tightly controlled, and what consequences does it bear for other types of outcomes of control?

\subsection{Limitations}

Our research is not without limitations. Amongst other things it needs to be complemented with field study evidence and placed in other settings. First, although the experimental case design allows us to systematically elaborate and isolate gender combinations in the supervisor-subordinate dyad, this is a fictional case picked out of a much more complex social environment that actual in vivo studies would meet. Second, our sample consists of relatively young and highly educated people in Sweden and this context might have limitations in generalisability. Sweden is often regarded as one of the most gender-equal societies in the world (fourth place according to UN statistics, UNDP 2013) and scores low on Hofstede's masculinity dimension (Hofstede 2015). In that sense, our sample of respondents could be described as a least likely case (in a relative sense) when it comes to detecting gender bias effects, and investigations in other societies where gender roles are even more pervasive and more evident, may reveal other effects. Social-role theory as such is a general theory, but when polarising the control context and gender roles into male and female types the wider context in which these polarisations are made consists of nuances that may be lost. Even if gender differences exist and femininity and masculinity are relevant aspects for understanding behaviour in organisations in most societies, gender roles and the effects they cause are social and context-specific constructions and our context may not be generalisable to all other contexts.

A more general emerging question is the extent to which tight control per se arouses stereotypical thinking. It is not unlikely that other types of performance evaluation, control design and use attributes affect gender bias differently (Eagly and Karau 2002; Parker 2008). For our purposes we made the design and use of the control system a constant. We selected a well-known and frequently explored control context (type) (Van der Stede 2001) that is agentic, autocratic and typically masculine in its approach and explored the role of gender in that context. Future research could subsequently focus on the association between variation in control and variation in stereotyping, in order to reveal how, why and when gender differences matter the most (or least). For example, does loose control (compared to tight control) or an enabling design (compared to a coercive design) make gender differences less (more) prevalent? The question remains as to what role gender plays in such loose or enabling features of control.

When studying gender and claiming that there are (statistically) significant gender differences, one may fall into the trap of reproducing and strengthening stereotypes about such differences. If looked at from the outside, and disregarding the $p$ values, 
it is probably as fair to say that there seem to be quite small differences between men and women in this study. It is important to note that, statistically, we have been able to prove that in some instances the hypothesis that there is no (zero) difference $\left(\mathrm{H}_{0}\right)$ is false, and with logic then inferred that there are differences. This is the method of hypothesis testing that is used to assess the importance of variables in research, be it degree of formality, type of control or the gender of a supervisor. Whether this means that men and women really differ in perceptions utterly becomes a philosophical question. Are we more similar than dissimilar, and are potential dissimilarities important enough to really indicate a difference? Two things are clear from our study: (1) claiming that there are absolutely no (zero) gender differences is false and (2) for subordinates having a female supervisor the gender differences, in some instances, also become practically significant.

Notwithstanding the limitations and suggestions for future research, we believe that the findings from our experiment raise interesting questions for both practitioners and researchers to reflect upon. They show that when researching perceptions of control in supervisor-subordinate dyads in the accounting literature, theorising about gender and gender roles in relation to the roles of supervisors and subordinates in that particular context may, indeed, add to our understanding of management control practices and outcomes. In particular our results demonstrate that the gender of supervisors and subordinates, and particularly different combinations of them, are important, but omitted variables in previous research on fairness and trust perceptions of formal and tight management controls. As a more critical point, our study shows that the role of supervisor gender in tight control contexts does not easily and directly resonate with commonly held views (stereotypes) of female supervisors executing tight control and expressing agentic behaviour. The processes seem to be more intricate and it is in dyads containing a female supervisor that subordinate gender differences becomes most salient. The study of gender and gender roles in the supervisor-subordinate dyad, thus, seem to be an interesting and promising area for future management control research to explore in greater depth.

Acknowledgements Open access funding provided by Karlstad University.

Open Access This article is distributed under the terms of the Creative Commons Attribution 4.0 International License (http://creativecommons.org/licenses/by/4.0/), which permits unrestricted use, distribution, and reproduction in any medium, provided you give appropriate credit to the original author(s) and the source, provide a link to the Creative Commons license, and indicate if changes were made.

\section{Appendix}

Case (Translated from Swedish to English by the authors)

Transporter Inc. is a well-established company operating in the freight and cargo business. The headquarters is located in Kungsbacka outside the city of Gothenburg. The company employs approximately 950 employees and in the year 2012 the turnover was 982,000,000 Swedish Krona. The company is divided into three business areas, the Business Units (BU): 1) International Transport, 2) Domestic Transport and 3) Flexible Transport. All BUs are investment centres, which means that they are responsible for their own revenue and expenses, but also for many of their investments and assets. 
The units are mainly evaluated based on a return on investment measure (ROI) (net profit/invested capital).

The Flexible Transport BU offers fast and flexible solutions for lighter cargo, mainly using cars but also smaller trucks. In recent years the unit has experienced problems with profitability and the situation has become more and more precarious. Despite lowered targets the unit finds it difficult to reach the required returns set by corporate management (see Table below).

\begin{tabular}{lllc}
\hline Year & $\begin{array}{l}\text { Target }(\%) \\
\text { ROI }\end{array}$ & $\begin{array}{l}\text { Result }(\%) \\
\text { ROI }\end{array}$ & $\begin{array}{l}\text { Deviation (\%) } \\
\text { ROI }\end{array}$ \\
\hline 2008 & 14.00 & 14.30 & 0.30 \\
2009 & 14.00 & 13.10 & -0.90 \\
2010 & 13.30 & 11.50 & -1.80 \\
2011 & 12.00 & 10.10 & -1.90 \\
2012 & 12.00 & 10.00 & -2.00 \\
\hline
\end{tabular}

Both corporate management and the manager responsible for the BU, [Peter Berg/Petra Berg], have all, according to their own statements, worked hard to try to improve profitability, although with little success. Basically, the corporate head managers trust the BU and have confidence that [Peter Berg/Petra Berg] does the best [he/she] can, but eventually they need to decide if they are going to retain the unit or change it entirely. In accordance with this direction, they have decided to appoint a new position at the corporate head office responsible for an additional evaluation of the BU Flexible transports. The person in this position is [Kristina Brink/Markus Brink]. With a degree from Stockholm School of Economics, [he/she] has worked two years as a strategic business controller at the Volvo consortium before [he/she] was appointed to the new position at Transport Inc. [Kristina/Markus] quickly arranged a meeting with [Peter/Petra] and described how [he/she] will deal with the forthcoming budget process.

Roughly speaking, this implies that [he/she] forces [Peter/Petra] to come up with a very detailed budget, broken down into many budget items. [Kristina/Markus] also declares that [he/she] requires weekly meetings where [Peter/Petra] informs [him/her] about changes in revenues and costs, and future prognoses. In addition [he/she] requires monthly budget reconciliations, where [Peter/Petra] needs to comment in writing on any deviations, budget-item by budget-item. In order to further encourage [Peter/Petra] (as head of the BU) and other subordinates in the BU to feel committed to and motivated by the budget, [he/she] has an approval from corporate management that [he/she] can introduce performance based compensation for [Peter/Petra] related to how well [he/she] reach the budget. [Peter/Petra] who has a desire to appear performance oriented, accepts this. [Kristina/Markus] makes it clear to [Peter/Petra] that [he/she] and the corporate management will under no circumstances accept negative budget deviations, and if this happens it will have consequences for [Peter's/Petra's] compensation and the overall evaluation of the BU. [Kristina/Markus] is not involved in the budget planning process and setting of budget targets, this takes place in negotiation between [Peter/Petra] and the corporate managers. [Kristina/Markus] has however made it clear 
to corporate managers that [he/she] thinks that [Peter's/Petra's] unit is able to perform as they did 2008 and 2009, and recommended that the corporate managers set the ROI target at approximately 14\%. Corporate managers are impressed with the work accomplished by [Kristina/Markus] and choose to follow [his/her] suggestion and set the target at $14 \%$ ROI.

In order to satisfy [Kristina/Markus] and the corporate management and to reach the required return, [Peter/Petra] realise that [he/she] needs to cut costs dramatically, because there is no way to increase the sales in the very short term. To cut costs dramatically demands some tough decisions from [Peter/Petra]. [Peter/Petra] is aware that neither corporate managers nor [Kristina/Markus] have full insight into how the financial accounts are made, instead they base their analysis primarily on the reports [he/she] provides. Except for revising driving schedules and fuel agreements (gas/diesel), [Peter/Petra] considers changing the rules on depreciation (from 6 to 10 years) for certain key assets (vehicles) and thus, as a purely accounting tactic, decreasing the cost of depreciation and, if only temporarily, make reaching the targets set by the corporate head easier. Rules and accounting praxis do not forbid [him/her] from doing that. [Peter/Petra] realises, however, that it is probably not completely honest to corporate management and [Kristina/Markus] to do so, but much is at stake; both for [him/her] personally and for all subordinates at the unit. [Kristinas'/Markus'] message was crystal clear.

We are now interested in your opinion/view about the way you think [Peter/Petra] will behave/act in the end.

Please answer the questions below.

Question 1.

How likely do you consider it that [Peter/Petra] will change the rules on depreciation from 6 to 10 years?

Please indicate the likelihood from 0 to $100 \%$.

Question 2.

Imagine that you are in [Peter's/Petra's] position. How likely do you consider it that you choose to change the rules on depreciation from 6 to 10 years?

Please indicate the likelihood from 0 to $100 \%$.

Question 3.

We also want to know how you judge the evaluation and control that [Kristina/ Markus] and the corporate management have introduced.

A. To what extent do you agree with the following statements? (Evaluation Fairness) (Totally disagree 1 - to totally agree 7):

The evaluation process to determine [Peter's/Petra's] compensation is fair.

Budget targets for [Peter/Petra] are set in a fair manner.

[Peter/Petra] is evaluated in a fair manner.

[Peter's/Petra's] is treated with dignity and respect.

B. To what extent do you agree with the following statements?(1-7) (Trust in Management) (Totally disagree 1- to totally agree 7):

In cases when [Kristina/Markus] and corporate managers take decisions against [Peter's/Petra's] interests, the decisions are justified and right. 
[Peter's/Petra's] superiors will fully and honestly keep [him/her] informed about everything that concerns [his/hers] unit.

Corporate managers seem to care a lot about [Peter's/Petra's] needs and desires.

Corporate managers and [Kristina/Markus] will act in favour of [Peter/Petra] and [his/her] unit.

C. How intrusive and strict would you say the evaluation and control that [Peter/Petra] experiences (1-7) is?

D. To what degree do you agree with the following statement?:

Tight control between upper management and departments, in the manner that has been described in the example above, is an appropriate mean to control departments in organisations (1-7) (Tables 4, 5).

Table 4 Descriptive statistics per experimental group

\begin{tabular}{llllr}
\hline Evaluation fairness & Min & Max & Mean & Std.dev \\
\hline A & 1.0 & 6.25 & 2.88 & 1.27 \\
B & 1.75 & 6.25 & 3.81 & 1.09 \\
C & 1.0 & 6.0 & 2.95 & 1.17 \\
D & 1.0 & 7.0 & 3.32 & 1.34 \\
Trust in Management & & & & \\
A & 1.0 & 5.25 & 2.73 & 0.97 \\
B & 1.25 & 6.25 & 3.48 & 1.29 \\
C & 1.0 & 4.75 & 2.91 & 0.94 \\
D & 1.0 & 4.75 & 2.97 & 1.02
\end{tabular}

Age

$\begin{array}{lllll}\text { A } & 20 & 26 & 22.41 & 1.54 \\ \text { B } & 20 & 29 & 23.45 & 2.17 \\ \text { C } & 20 & 47 & 23.92 & 4.05 \\ \text { D } & 20 & 38 & 24.35 & 3.38\end{array}$

Generalised Trust

$\begin{array}{lllll}\mathrm{A} & 2 & 7 & 4.57 & 1.11 \\ \mathrm{~B} & 2 & 7 & 4.36 & 1.22 \\ \mathrm{C} & 1 & 7 & 4.35 & 1.18 \\ \mathrm{D} & 2 & 7 & 4.00 & 1.35\end{array}$

Social Capital

$\begin{array}{lllll}\text { A } & 0 & 6 & 1.33 & 1.38 \\ \text { B } & 0 & 6 & 1.85 & 1.49 \\ \text { C } & 0 & 6 & 1.33 & 1.32 \\ \text { D } & 0 & 6 & 2.08 & 1.37\end{array}$

Groups: A = Fem supervisor/fem Moral stand

subordinate; $\mathrm{B}=$ Fem

supervisor/male subordinate; $\mathrm{C}$

\begin{tabular}{lllll} 
A & 0 & 100 & 42.83 & 28.12 \\
B & 0 & 100 & 54.47 & 30.60 \\
C & 0 & 90 & 47.06 & 25.40 \\
D & 0 & 100 & 62.71 & 30.32 \\
\hline
\end{tabular}


Table 5 Correlation matrix

\begin{tabular}{|c|c|c|c|c|c|c|c|}
\hline Fairness & Fairness & Trust & Age & GT & $\mathrm{SC}$ & MS & SubGen \\
\hline Trust & $0.599 * *$ & & & & & & \\
\hline Age & -0.109 & -0.044 & & & & & \\
\hline Generalised trust & 0.028 & 0.077 & -0.046 & & & & \\
\hline Social capital & -0.127 & -0.104 & 0.087 & -0.062 & & & \\
\hline Moral stand & 0.083 & 0.102 & 0.062 & -0.132 & -0.006 & & \\
\hline Subord. gender & $0.255^{* *}$ & $0.182 *$ & 0.115 & -0.112 & $.228 * *$ & $.232 * *$ & \\
\hline Super. gender & -0.088 & -0.079 & $.196^{* *}$ & -0.115 & 0.038 & 0.101 & -0.021 \\
\hline
\end{tabular}

** Correlation is significant at the 0.01 level (2-tailed).

* Correlation is significant at the 0.05 level (2-tailed)

\section{References}

Akerlof, G. A., \& Kranton, R. E. (2005). Identity and the economics of organizations. The Journal of Economic Perspectives, 19, 9-32.

Avolio, B. J. (1999). Full leadership development: Building the vital forces in organizations. Thousand Oaks, CA: Sage.

Bakan, D. (1966). The duality of human existence: An essay on psychology and religion. Chicago: Rand McNally.

Bass, B. M. (1985). Leadership and performance beyond expectation. New York: Free Press.

Baldvinsdottir, G., Hagberg, A., Johansson, I.-L., Jonäll, K., \& Marton, J. (2011). Accounting research and trust: A literature review. Qualitative Research in Accounting and Management, 8, 382-424.

Berry, A. J., Coad, A. F., Harris, E. P., \& Otley, D. T. (2009). Emerging themes in management control: A review of recent literature. The British Accounting Review, 41, 2-20.

Buchana, N. R., Crosonb, R. T. A., \& Solnick, S. (2008). Trust and gender: An examination of behavior and beliefs in the investment game. Journal of Economic Behavior and Organization, 68, 466-476.

Cheng, M., \& Coyte, R. (2014). The effects of incentive subjectivity and strategy communication on knowledge-sharing and extra-role behaviours. Management Accounting Research, 25, 119-130.

Chenhall, R. H. (2003). Management control systems design within its organizational context: Findings from contingency-based research and directions for the future. Accounting, Organizations and Society, $28,127-168$.

Cohen, J., Cohen, P., West, S. G., \& Aiken, L. S. (2003). Applied multiple regression and correlation analysis for the behavioral sciences (3rd ed.). Hillsdale, NJ: Erlbaum.

Coletti, A. L., Sedatole, K. L., \& Towry, K. L. (2005). The effect of control systems on trust and cooperation in collaborative environments. The Accounting Review, 80(2), 477-500.

Colquitt, J. A. (2001). On the dimensionality of organizational justice: A construct validation of a measure. Journal of Applied Psychology, 86, 386-400.

Colquitt, J. A., Conlon, D. E., Wesson, M. J., Porter, C. O. L. H., \& Ng, K. Y. (2001). Justice at the millennium: A meta-analytic review of 25 years of organizational justice research. Journal of Applied Psychology, 86, 425-445.

Croson, R., \& Gneezy, U. (2009). Gender differences in preferences. Journal of Economic Literature, 47(2), $448-474$.

Cugueró-Escofet, N., \& Rosanas, J. M. (2013). The just design and use of management control systems as requirements for goal congruence. Management Accounting Research, 24, 23-40.

Eagly, A. H. (1987). Sex differences in social behavior: A social-role interpretation. Hillsdale, NJ: Erlbaum.

Eagly, A. H., Makhijani, M. G., \& Klonsky, B. G. (1992). Gender and the evaluation of leaders: A metaanalysis. Psychological Bulletin, 111, 3-22.

Eagly, A. H. (2009). The his and hers of prosocial behavior: An examination of the social psychology of gender. American Psychologist, 64(8), 644-658. 
Eagly, A. H., \& Johannesen-Schmidt, M. C. (2001). The leadership styles of women and men. Journal of Social Issues, 57, 781-797.

Eagly, A. H., \& Johnson, B. T. (1990). Gender and leadership style: A meta-analysis. Psychological Bulletin, $108(2), 233-256$.

Eagly, A. H., \& Karau, S. J. (2002). Role congruity theory of prejudice toward female leaders. Psychological Review, 109, 573-598.

Eagly, A. H., \& Carli, L. L. (2003). The female leadership advantage: An evaluation of the evidence. The Leadership Quarterly, 14, 807-834.

Ellyson, S. L., Dovidio, J. F., \& Brown, C. E. (1992). The look of power: Gender differences in visual dominance behavior. In C. L. Ridgeway (Ed.), Gender, interaction, and inequality (pp. 50-80). New York: Springer.

Finch, J. (1987). The vignette technique in survey research. Sociology, 21, 105-114.

Fornell, C., \& Larcker, D. F. (1981). Evaluating structural equation models with unobservable variables and measurement errors. Journal of Marketing Research, 18, 39-50.

Fortin, M. (2008). Perspectives on organizational justice: concept clarification, social context integration, time and links with morality. International Journal of Management Reviews, 10, 93-126.

Glick, P., \& Fiske, S. T. (1999). Sexism and other "isms": Interdependence, status, and the ambivalent content of stereotypes. In W. B. Swann, J. H. Langlois, \& L. A. Gilbert (Eds.), Sexism and stereotypes in modern society: The gender science of Janet Taylor Spence (pp. 193-221). Washington, DC: American Psychological Association.

Goldberg, P. (1968). Are women prejudiced against women? Transaction, 5, 316-322.

Gopalakrishnan, M., Libby, T., Samuels, J. A., \& Swenson, D. (2015). The effect of cost goal specificity and new product development process on cost reduction performance. Accounting, Organizations and Society, 42, 1-11.

Hartmann, F. G. H. (2000). The appropriateness of RAPM: Toward the further development of theory. Accounting, Organizations and Society, 25, 451-482.

Hartmann, F. G. H., \& Maas, V. S. (2010). Why business unit controllers create budget slack: Involvement in management, social pressure, and Machiavellianism. Behavioral Research in Accounting, 22(2), 27-49.

Hartmann, F. G. H., \& Slapničar, S. (2009). How formal performance evaluation affects trust between superior and subordinate managers. Accounting, Organizations and Society, 34, 722-737.

Hartmann, F. G. H., \& Slapničar, S. (2012). The perceived fairness of performance evaluation: The role of uncertainty. Management Accounting Research, 23(1), 17-33.

Henseler, J., Ringle, C., \& Sarstedt, M. (2015). A new criterion for assessing discriminant validity in variance-based structural equation modeling. Journal of the Academy of Marketing Science, 43, 115135.

Hofstede, G. (2015). Cultural Compass ${ }^{\text {TM }} .22$ Jan 2015.

Hopwood, A. G. (1972). An empirical study of the role of accounting data in performance evaluation. Journal of Accounting Research, 10, 156-182.

Hull, R. P., \& Umansky, P. H. (1997). An examination of gender stereotyping as an explanation for vertical job segregation in public accounting. Accounting, Organizations and Society, 22, 507-528.

Iqbal, M. Z., Akbar, S., \& Budhwar, P. (2015). Effectiveness of performance appraisal: An integrated framework. International Journal of Management Reviews, 17, 510-533.

Jeanquart-Barone, S., \& Sekaran, U. (1994). Effects of supervisor's gender on American women's trust. The Journal of Social Psychology, 4, 253-255.

Johansson, T., \& Siverbo, S. (2014). The appropriateness of tight budget control for public sector organizations facing budget turbulence. Management Accounting Research, 25, 271-283.

Johansson, I.-L., \& Baldvinsdottir, G. (2003). Accounting for trust: Some empirical evidence. Management Accounting Research, 14, 171-186.

Koenig, A. M., Eagly, A. H., Mitchell, A. A., \& Ristikari, T. (2011). Are leader stereotypes masculine? A meta-analysis of three research paradigms. Psychological Bulletin, 137(4), 616-642.

Kumlin, S., \& Rothstein, B. (2010). Questioning the new liberal dilemma: Immigrants, social networks, and institutional fairness. Comparative Politics, 43(1), 63-80.

Kunz, J. (2015). Objectivity and subjectivity in performance evaluation and autonomous motivation: An exploratory study. Management Accounting Research, 27, 27-46.

Kunz, J., \& Linder, S. (2012). Organizational control and work effort-Another look at the interplay of rewards and motivation. European Accounting Review, 21, 591-621. 
Lau, C. M., \& Buckland, C. (2001). Budgeting-the role of trust and participation: A research note. Abacus, 37(3), 369-388.

Lau, C. M., \& Sholihin, M. (2005). Financial and nonfinancial performance measures: How do they affect job satisfaction? The British Accounting Review, 37, 389-413.

Lau, C. M., \& Tan, S. L. C. (2006). The effects of procedural fairness and interpersonal trust on job tension in budgeting. Management Accounting Research, 17, 171-186.

Lau, C. M., Wong, K. M., \& Eggleton, I. R. C. (2008). Fairness of performance evaluation procedures and job satisfaction: The role of outcome-based and non-outcome-based effects. Accounting and Business Research, 38, 121-135.

Mandel, H. (2012). Winners and losers: The consequences of welfare state policies for gender wage inequality. European Sociology Review, 28, 241-262.

Merchant, K. A., \& Van der Stede, W. A. (2012). Management control systems: Performance measurement, evaluation, and incentives. London: Prentice Hall.

Mayer, R. C., \& Davis, J. H. (1999). The effect of the performance appraisal system on trust for management: A field quasi-experiment. Journal of Applied Psychology, 84(1), 123-136.

Mayer, R. C., Davis, J. H., \& Schoorman, D. (1995). An integrative model of organizational trust. Academy of Management Review, 20, 709-734.

Miller, A. S., \& Mitamura, T. (2003). Are surveys on trust trustworthy? Social Psychology Quarterly, 66, $62-70$.

Muriel, N., \& Vesterlund, L. (2011). Gender and competition. Annual Review of Economics, 3, 601-630.

Otley, D. T. (1978). Budget use and managerial performance. Journal of Accounting Research, 16(1), 122-149.

Otley, D. T., Broadbent, J. M., \& Berry, A. J. (1995). Research in management control: An overview of its development. British Journal of Management, 6, S31-S34.

Parker, L. D. (2008). Strategic management and accounting processes: Acknowledging gender. Accounting, Auditing and Accountability Journal, 21, 611-631.

Putnam, R. (1993). Making democracy work: Civic tradition in modern Italy. Princeton: Princeton University Press.

Putnam, R. (2000). Bowling alone: The collapse and revival of American community. New York: Simon and Schuster.

Read, W. H. (1962). Upward communication in industrial hierarchies. Human Relations, 15, 3-16.

Ridgeway, C. L. (1991). The social construction of status value: Gender and other nominal characteristics. Social Forces, 70, 367-386.

Ridgeway, C. L. (2001). Gender, status, and leadership. Journal of Social Issues, 57(4), 637-655.

Ridgeway, C. L., Backor, K., Li, Y. E., Tinkler, J. E., \& Erickson, K. G. (2009). How easily does a social difference become a status distinction? Gender matters. American Sociology Review, 74, 44-62.

Ridgeway, C. L., \& Balkwell, J. W. (1997). Group processes and the diffusion of status-value beliefs. Social Psychology Quarterly, 60, 14-31.

Rudman, L. A., \& Glick, P. (2001). The Society for the psychological study of social issues. Journal of Social Issues, 57(4), 743-762.

Rudman, L. A., \& Kilanski, S. E. (2000). Implicit and explicit attitudes toward female authority. Personality and Social Psychology Bulletin, 26, 1315-1328.

Ross, A. (1994). Trust as a moderator of the effect of performance evaluation style on job-related tension: A research not. Accounting, Organization and Society, 19, 629-635.

Schein, V. E. (2001). A global look at psychological barriers to women's progress in management. Journal of Social Issues, 57, 675-688.

Schoorman, F. D., Mayer, R. C., \& Davis, J. H. (2007). An integrative model of organizational trust: Past, present and future. Academy of Management Review, 32, 344-354.

Sholihin, M., \& Pike, R. (2009). Fairness in performance evaluation and its behavioural consequences. Accounting and Business Research, 39, 397-413.

Spence, J. T., \& Buckner, C. E. (2000). Instrumental and expressive traits, trait stereotypes, and sexist attitudes. Psychology of Woman Quarterly, 24, 44-62.

Stedham, Y., Yamamura, J., \& Beekum, R. (2007). Gender differences in business ethics: Justice and relativist perspectives. Business Ethics: A European Review, 16, 163-174.

Sweeney, P. D., \& McFarlin, D. B. (1993). Workers' evaluation of the 'ends' and the 'means': An examination of four models of distributive and procedural justice. Organizational Behavior and Human Decision Processes, 55, 23-40. 
Swim, J., Borgida, E., Maruyama, G., \& Myers, D. G. (1989). Joan McKay versus John McKay: Do gender stereotypes bias evaluations? Psychological Bulletin, 105, 409-429.

Taylor, B. J. (2006). Factorial surveys: Using vignettes to study professional judgment. British Journal of Social Work, 36, 1187-1207.

Tenbrunsel, A. E., \& Messick, D. M. (1999). Sanctioning systems, decision frames, and cooperation. Administrative Science Quarterly, 44(4), 684-707.

United Nations Human Development Reports. (2013). United Nations Development Program, New York.

Uslaner, E. M. (2000). Producing and consuming trust. Political Science Quarterly, 115, 569-590.

Van der Stede, W. A. (2000). The relationship between two consequences of budget controls: Budget slack creation and managerial short-term orientation. Accounting, Organizations and Society, 25, 609-622.

Van der Stede, W. A. (2001). Measuring 'tight budget control'. Management Accounting Research, 12, $119-137$.

Wennblom, G. (2012). Mapping management accounting and trust. An extended literature review. Örebro Studies in Business Dissertations 3, Örebro University. http://www.diva-portal.org/smash/get/diva2: 571891/FULLTEXT02.pdf.

Vosselman, E. G. J., \& van der Meer-Kooistra, J. (2009). Accounting for control and trust in inter-firm transactional relationships. Accounting, Organizations and Society, 34, 267-283.

Whitener, E. M., Brodt, S. E., Korsgaard, M. A., \& Werner, J. M. (1998). Managers as initiators of trust: An exchange relationship framework for understanding managerial trustworthy behavior. Academy of Management Review, 23, 513-530. 